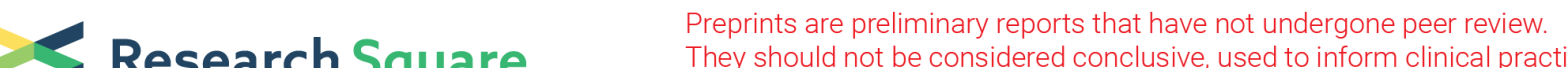 $\begin{array}{ll}\text { Research Square } & \text { They should not be considered conclusive, used to inform clinical practice, } \\ \text { or referenced by the media as validated information. }\end{array}$
}

\section{Differences on Pyrexia Related Immune Responses between SARS-CoV-2 and Influenza-A-infected Children: A Retrospective Study}

\section{Shanglong Kou}

The Third People's Hospital of Shenzhen

\section{Senlin Zhan}

The Third People's Hospital of Shenzhen

Xiaohe Li

The Third People's Hospital of Shenzhen

Mingxia Zhang

The Third People's Hospital of Shenzhen

\section{Guofang Deng}

The Third People's Hospital of Shenzhen

\section{Yanchao Pan ( $\nabla$ panychao@126.com )}

The Third People's Hospital of Shenzhen https://orcid.org/0000-0003-4092-8295

Jing Yuan

The Third People's Hospital of Shenzhen

\section{Research article}

Keywords: SARS-CoV-2, asymptomatic infection, Influenza A infection, body temperature, hypoinflammatory responses

Posted Date: January 12th, 2021

DOI: https://doi.org/10.21203/rs.3.rs-54254/v2

License: (c) (1) This work is licensed under a Creative Commons Attribution 4.0 International License. Read Full License 


\section{Abstract}

Background: The ongoing pandemic of COVID-19 has led to an unprecedented global crisis with problems of fragmentation in healthcare services in many severely affected countries. A key issue is distinguishing the clinical manifestations of COVID-19 from other respiratory infectious disease, especially in children and teens.

Methods: To provide precise and comprehensive information on SARS-CoV-2 infected children, a total 62 hospitalized patients, aged from 1 to 14 years old and confirmed with the infection of either SARS-CoV-2 or influenza A virus, were enrolled from September 2019 to February 2020. The epidemiological, clinical and laboratory characteristics, as well as the outcomes of these pediatric patients were collected, followed by comparisons and regression analysis on clinical features and hematological parameters among the COVID-19 patients and the flu patients.

Results: We reported that SARS-CoV-2 infected children showed less fever $(43.33 \%$ vs $100 \%, p<0.001)$ with mild elevation of the body temperature $(p<0.001)$, as well as attenuated inflammatory responses in comparison with patients with influenza A infection. We further showed the significant correlations between initial body temperature and multiple immune parameters (white blood cell counts and inflammatory markers) among SARS-CoV-2 infected children.

Conclusions: Children with SARS-CoV-2 infection were more likely to have mild symptoms and relatively slow progression with a hypo-inflammatory response. Furthermore, the correlation results suggested that distinct immune responses were involved during SARS-CoV-2 infection.

\section{Background}

Starting from 1918, influenza A pandemic has occurred four times, resulting in more than 30 million infections and 20 thousand deaths, and continued to spread in the world as a seasonal flu virus. Since last December 2019, the SARS-CoV-2 infection, represented as much more contagious and infectious disease, has outbreak and rapidly spanned over the world with over 70 million cases and 1.6 million deaths by the middle of December 2020.

Children are at high risk of influenza $A$ infection, which commonly causes the respiratory tract related complications with fever, cough, runny nose, as well as sore throat, and contributed to a prevalence of over $20 \%$ in children every year [1]. In some cases they developed to lethal pneumonia by triggering an extreme inflammatory response in the body, and even leaded to life threatening sepsis [2]. Similar to influenza, COVID-19 is characterized by acute pneumonia symptoms including fever, dry cough, myalgia and dyspnea and the severity was considered associated with age and comorbidities [3].

Although predominant children and younger teen with SARS-CoV-2 infection represented mild to moderate respiratory illness [4,5]with less than $1 \%$ of confirmed cases [6], there were several cases developing into multisystem inflammatory syndrome with high fever and cytokine storm [7]. 
To better understand the immunological reaction to SARS-CoV-2 in children, we provide precise and comprehensive comparisons on SARS-CoV-2 and influenza A virus infected children to elucidate the relationship between thermal activation and immune responses in COVID-19 infections.

\section{Methods}

\section{Population}

In this retrospective cohort study, all subjects were collected from inpatient populations in Shenzhen Third People's Hospital from September 2019 to February 2020.All the cases met the following recruitment criteria on the definition of SARS-CoV-2 and influenza infection, respectively.

\section{Recruitment Criteria}

1. The admitted participants aged from 1 to 14 years.

2. The potential participants met the definitions for either SARS-CoV-2 or influenza infections.

Definition for influenza cases in our study: (1) onset of at least one of the following systemic symptoms: fever, headache, myalgia or malaise; (2) At least one of the following three respiratory symptoms: cough (dry cough), sore throat or dyspnea; (3) Laboratory criteria on detection of influenza (A and B) virus nucleic acid in a clinical specimen. Any person meeting the (1) and (3) or (2) and (3) will be regarded as confirmed case of influenza.

Definition for COVID-19 cases in our study. Clinical criteria: (1) Acute onset of fever or cough (dry cough); (2) The respiratory infection with the following symptoms: cough, fever, dyspnea; (3) Radiological evidence showing lesions compatible with COVID-19;

Epidemiological criteria: (1) Once close contact with a COVID-19 confirmed case in the last 14 days prior to onset of symptoms; (2) Residing or working in or travel to an area with high risk of transmission in the last 14 days. Laboratory criteria: A positive result on detection of SARS-CoV-2 nucleic acid in a clinical specimen. Any individual meeting the laboratory criteria with either clinical or epidemiological criteria will be regarded as the confirmed case.

\section{Exclusion Criteria}

(1) Under the age of 1 or Over the age of 14; (2) Prior receipt of any vaccine in the past 6 months; (3) Have received immunoglobulins and/or any blood products within three months; (4) History of chronic inflammatory disease (rheumatological disease, autoimmune disease); (5) Use of antipyretic medication (acetaminophen or ibuprofen) within 72 hours; (6) Confirmed with SARS-CoV-2/influenza or influenza A/B co-infections; (7) History of hypersensitivity to gentamicin or vancomycin, other aminoglycoside antibiotics; (8) Missing data on medical records; (9) Other medical or psychiatric conditions that may interfere with study participation; 


\section{Data Collection}

Pharyngeal swab samples were collected in a tube with $150 \mu \mathrm{L}$ of virus preservation solution, followed by total RNA extraction. Influenza A And B Viruses Real Time PCR Kit (Bioperfectus Technologies Co., Ltd., China) was used for the detection of influenza $A$ and $B$ viruses. Coronavirus (2019-nCoV) RNA Detection Kit (PCR Fluorescence probing) manufactured by Da An Gene Co., Ltd. and approved by China's National Medical Products Administration, was used for SARS-CoV-2 virus testing in pharyngeal swabs.

Conditions for the amplifications include reverse transcription at $50^{\circ} \mathrm{C}$ for $15 \mathrm{~min}$, pre-denaturation at $95^{\circ} \mathrm{C}$ for $15 \mathrm{~min}$, followed by 45 cycles of $94^{\circ} \mathrm{C}$ for $15 \mathrm{~s}$ and $55^{\circ} \mathrm{C}$ for $45 \mathrm{~s}$ for fluoresce detection. The receiver operating characteristic curve analysis was used to determine the optimal threshold cut-off value. And a cycle threshold (Ct) value $\leq 40$ was defined as a positive test. Demographic and clinical data of involved patients was derived from electronic medical records. The samples for peripheral blood were collected on admission day as well as during the hospitalization. The routine blood test was performed by Sysmex XT2000i automated hematology analyzer (Sysmex Corporation). Inflammatory biomarker assays were run on ARCHITECT i2000 SR analyzer (Abbot Diagnostics) according to the protocols recommended by the manufacturer. In brief, the assay is a two-step protocol. In step 1, $25 \mu \mathrm{L}$ of sample was incubated with antigen coated paramagnetic microparticles, followed by a wash step. The second step incorporated the addition of acridinium-labeled conjugate to create a reaction mixture. After a further washing, trigger solutions were added to create a chemiluminescent reaction. The light emission was then measured as a relative light unit which was directly proportional to the amount of target in the sample.

\section{Ethical Approval}

This study was approved by Shenzhen Third People's Hospital Ethics Committee and informed consent in influenza cohort was obtained from parents or guardians. For COVID-19 patients, written informed consent was waived by the Ethics Commission. Any data we collected and analyzed was derived from clinical raw record without any intervention and influence on clinical treatment. And no additional collection of human samples or genetic resource materials was performed in our study.

\section{Study Procedures}

Shown as in Figure 1, age- and definition-matched COVID-19 patients and influenza infected patients were recruited as two separate groups. Overall, 4 COVID-19 cases with incomplete information were excluded from further analysis, while complete data were available for 30 COVID-19 cases and 36 influenza cases, respectively. Furthermore, 4 influenza B cases were not taken into consideration because the sample size is too small to yield statistical significances. Totally, 30 SARS-CoV-2 and 32 influenza A confirmed cases were enrolled. In particular, 5 of SARS-CoV-2 infected pediatric patients, matching the inclusion criteria of our previous study, were included in another report [8]. The data were extracted from the electronic medical records, including demographic characteristics (age and sex), clinical signs and symptoms, as well as laboratory tests (routine blood test, blood chemistry and inflammatory marker assays). Fever was defined as an axillary temperature of $37.5^{\circ} \mathrm{C}$ or higher. All these information were double checked by two researchers independently. 


\section{Statistical Analysis}

Comparisons were conducted by using the Mann-Whitney non-parametric test. Mean \pm standard deviation (SD) and 95\% confidence interval were reported for normally distributed, continuous variables. Categorical variables were reported as counts and percentages. While for data not normally distributed, median with interquartile range (IQR) was used. Pearson correlation coefficients were used to assess the relation of inflammatory parameters and body temperatures. All statistical analysis was done on SPSS version 25 .

\section{Results}

The median age of 30 SARS-CoV-2-infected children was confirmed to be 5.29 years (IQR: 3.04-7.61), while that of 32 children infected with influenza A was 7.09 years (4.08-11.05) (shown in Table 1). Overall, $63.33 \%$ of children with SARS-CoV-2 infection were girls and the influenza A group showed the opposite portion with $59.38 \%$ of boys. Comparison on onset symptoms showed that instead of $100 \%$ exhibition of both fever and cough in children infected with influenza $A$, only $43.33 \%(p<0.001)$ and $26.67 \%(p<0.001)$ patients represented fever and cough respectively in SARS-CoV-2 cases.

On admission day, lymphocyte count and serum lactate dehydrogenase (LDH) were elevated dramatically beyond the normal ranges in both two groups. One the other hand, compared with extremely higher levels of serum C-reactive protein (CRP), procalcitonin (PCT) as well as erythrocyte sedimentation rate (ESR) in children infected with influenza A, those of SARS-CoV-2 cases were considered within the normal ranges. Particularly, SARS-CoV-2-infected children had significantly less severe neutrophilia with an average count of $29.6 \times 10^{\wedge} 9 / \mathrm{L}\left(95 \% \mathrm{Cl}: 20.06-38.72 \times 10^{\wedge} 9 / \mathrm{L}\right)$, while that of influenza A patients was as higher as $58.07 \times 10^{\wedge} 9 / \mathrm{L}\left(46.04-73.08 \times 10^{\wedge} 9 / \mathrm{L}\right)$.

Once they were admitted to hospital, $100 \%$ influenza-A-infected patients had fever with the average body temperature of $39.5^{\circ} \mathrm{C}\left(39.3-39.7^{\circ} \mathrm{C}\right)$. While only $13(43.3 \%)$ SARS-CoV-2-infected children exhibited with fever on a significantly lower $(p<0.001)$ average body temperature of $38.3^{\circ} \mathrm{C}\left(37.8-38.8^{\circ} \mathrm{C}\right)$. After 3 days of hospital stay, there remained 23 influenza-A-patients representing with continuous fever on average of $38.8^{\circ} \mathrm{C}\left(38.5-39.1^{\circ} \mathrm{C}\right)$. In contrast, only 5 SARS-CoV-2-infected children's body temperature were hotter than $37.5^{\circ} \mathrm{C}$ (shown as Figure $2 \mathrm{~A} \& \mathrm{~B}$ ). Simultaneously, with 3 days of hospital care, the influenza-Ainfected children showed significantly decreased WBC, neutrophil and lymphocyte counts (shown as Figure 2C-E). On the contrary, a rare change occurred in SARS-CoV-2 cases. Remarkably, both patients showed obviously elevated platelet levels (shown as Figure 2F). Besides, radiographical imaging indicated that typical pneumonia patterns of initial $23(71.88 \%)$ influenza-A-infected patients predominately had obvious improvements in 3-5 days. In contrast, 9 (30\%) SARS-CoV-2-infected children showed few changes in extent of the ground-glass opacities and another 2 children represented increased parenchymal density. Subsequently, all influenza-A-infected patients recovered after an average of 5.31 days (4.58-6.04) of hospitalization. Seven SARS-CoV-2-infected children were still in hospital with 15 to 21 days of current stays and the average length of hospital stay was 15.53 days (13.91-17.16). Further 
Pearson correlation analysis indicated that there were substantially significant positive correlations between the degree of body temperature and these immunological parameters on admission day in children with SARS-CoV-2 infection (shown in Table 2, WBC: $\mathrm{r}=0.414, p=0.028$; HB: $\mathrm{r}=-0.387, p=0.042$; CRP: $\mathrm{r}=0.509, p=0.011 ; \mathrm{PCT}: \mathrm{r}=0.51, p=0.013)$. Dissimilarly, only admission PCT level was significantly correlated with the body temperature of influenza-A-infected children.

\section{Discussion}

COVID-19 and influenza, sharing similar symptoms in initiation, were difficult to differentiate via clinical manifestations prior to viral identification. However, they represent with different protective measures, disease progression, therapies, as well as prognoses. First, human to human transmission of SARS-CoV-2 is much more easier compared to influenza A. The basic reproduction number for SARS-CoV-2 was estimated to be 2-4 [15-17], while the median value of that for seasonal influenza was about 1.28 [18]. In addition, the case fatality rate (CFR) of pandemic influenza $A$ was estimated to be far below $1 \%$ among young populations[19], and the morbidity and mortality rates increased in those with comorbidities [20]. In comparison, the overall death rate of COVID-19 is much higher than that of seasonal influenza with the worldwide CFR of about $2 \%-3 \%[21,22]$ and sharply decreasing to less than $0.002 \%$ in younger children [23-25]. Furthermore, some cases of influenza A and SARS-CoV-2 co-infection have been reported in patients with severe acute respiratory syndrome [26], multiple complications [27] and even a 4 month old infant [28]. It has been estimated that influenza A virus could increase diagnostic difficulties in SARSCoV-2 infected patients [29] and co-infections may result in a more severe complications or a fatal outcome in children [30]. Therefore, it is important to differentiate these two diseases via early clinical presentations in the pediatric population. The current study revealed that SARS-CoV-2-infected children predominately represented with low-grade fevers on average of $38.3^{\circ} \mathrm{C}\left(37.8-38.8^{\circ} \mathrm{C}\right)$ and less symptoms, while children infected with influenza A displayed a high grade fever with the average of $39.5^{\circ} \mathrm{C}(39.3-$ $39.7^{\circ} \mathrm{C}$ ) and the significantly higher levels of CRP and PCT, as well as the number of WBCs, especially neutrophils. We further demonstrated that the initial body temperatures of COVID-19 infected children were significantly correlated with multiple immune parameters (white blood cell counts, as well as inflammatory markers CRP and PCT). These findings were consistent with what previous studies[31] have suggested that majority of SARS-CoV-2-infected children presented as fever with inconspicuous changes in hematological parameters. Further studies on pathogenesis of COVID-19 may elucidate the underlying mechanisms.

SARS-CoV-2 infection was identified to activate the host innate immune system via the bindings of its spike glycoprotein (S-protein) to the angiotensin-converting enzyme 2 (ACE2) receptor and transmembrane protease serine 2 (TMPRSS2) [32,33], which engaged macrophages and monocytes to release cytokines and enhanced adaptive $T$ and $B$ cell immune response [34]. While influenza infection is initiated by adhesion of hemagglutinin ( $\mathrm{HA}$ ) to sialic acids on the epithelial cells, followed with activation of innate immune signaling and further production of cytokines via host pathogen recognition receptors (PRPs) $[35,36]$. Further gene expression analyses have identified the expression pattern of cytokines, cytokine receptors, as well as transcription factors in COVID-19 patients, which quite differs from that of 
influenza A infected patients [37, 38]. SARS-CoV-2 infections exhibited with TNF/IL-1 $\beta$-driven proinflammation and T cell apoptosis. In contrast, influenza A patients featured type I IFN-driven inflammatory regulation, which was co-existed in severe COVID-19 patients [37]. These results supported the clinical observations of cytokine storm in severe COVID-19 patients $[39,40]$ representing with lymphopenia and increased levels of pro-inflammatory cytokines, including TNF and IL-6. Here our results documented the mild elevation of the body temperature and less activated immune status in children with mild COVID-19.

In addition, in correspondence with recent cases of SARS-CoV-2-infected children with persistent fever showing multi-inflammatory syndrome like Kawasaki-like disease [14, 41], we speculate that nonsusceptibility of children to SARS-CoV-2 virus may lie in the low activity of immune response. Further explorations will contribute to the management and development of therapeutics for COVID-19 patients.

There were some limitations in the current study. First, flu activity typically starts from late September and increases from early November to next February, while encountering the sudden outbreak and rapid spread of COVID-19 in China at the end of 2019. The strict quarantine and lockdown measures in the COVID-19 pandemic inescapably reduced transmission of flu, which probably resulted in unavoidable bias. Second, in this retrospective study, SARS-Cov-2 confirmed cases were originated from several hospitals in Shenzhen, China, subsequently transferred to Shenzhen Third People's Hospital for quarantine and medical treatment. Whereas influenza A data came from an independent single center (Shenzhen Third People's Hospital). Data collection of the similar cohort would be better to avoid statistical disequilibrium.

\section{Conclusions}

We described the SARS-CoV-2-infected children with mild elevation of the body temperature and significantly lower levels of CRP and PCT, as well as decreased neutrophil count in comparison with influenza-A-infected children. We further documented the significant correlations between body temperature and multiple immune functional parameters in children with SARS-CoV-2 infection rather than influenza A. Our results clarify the less activated immune status in asymptomatic children with SARS-CoV-2 infection. Further explorations will contribute to the therapeutic management of patients with COVID-19.

\section{Abbreviations}

novel coronavirus disease

COVID-19

white blood cell

WBC 
hemoglobin

HB

albumin

ALB

alanine aminotransferase

ALT

aminotransferase

AST

lactate dehydrogenase

LDH

creatine kinase

CK

blood urea nitrogen

BUN

erythrocyte sedimentation rate

ESR

creatinine

$\mathrm{Cr}$

procalcitonin

C-reactive protein

PCT

CRP

\section{Declarations}

Ethical approval and consent to participate: 
This study was approved by Shenzhen Third People's Hospital Ethics Committee and informed consent in influenza cohort was obtained from parents or guardians. For COVID-19 patients, written informed consent was waived by the Ethics Commission. Any data we collected and analyzed was derived from clinical raw record without any intervention and influence on clinical treatment. And no additional collection of human samples or genetic resource materials was performed in our study.

\section{Consent for publication:}

All the authors mentioned in the manuscript have agreed for authorship, read and approved the manuscript, and given consent for submission and subsequent publication of the manuscript.

\section{Availability of data and materials:}

The datasets used and/or analyzed during the current study are available from the corresponding author on reasonable request.

\section{Competing interests:}

No financial or nonfinancial benefits have been received or will be received from any party related directly or indirectly to the subject of this article.

\section{Funding:}

This work was supported by Sanming Project of Medicine in Shenzhen (SZSM201512005).

\section{Authors' contributions:}

Shanglong Kou and Senlin Zhan contribute equally to this work. Jing Yuan and Yanchao Pan are cocorresponding authors. Shanglong Kou, Yanchao Pan conceptualized and designed the study, carried out the initial analyses, and drafted the initial manuscript. Senlin Zhan and Guofang Deng designed the data collection instruments, collected data and revised the manuscript. Xiaohe Li, Mingxia Zhang and Jing Yuan supervised data collection, and critically reviewed the manuscript for important intellectual content. 


\section{References}

1. Vaccines against influenza WHO position paper - November 2012. Wkly Epidemiol Rec 2012, 87(47):461-476.

2. Sellers SA, Hagan RS, Hayden FG, Fischer WA, 2nd: The hidden burden of influenza: A review of the extra-pulmonary complications of influenza infection. Influenza Other Respir Viruses 2017, 11(5):372-393.

3. Fang X, Li S, Yu H, Wang P, Zhang Y, Chen Z, Li Y, Cheng L, Li W, Jia H et al: Epidemiological, comorbidity factors with severity and prognosis of COVID-19: a systematic review and metaanalysis. Aging (Albany NY) 2020, 12(13):12493-12503.

4. Castagnoli R, Votto M, Licari A, Brambilla I, Bruno R, Perlini S, Rovida F, Baldanti F, Marseglia GL: Severe Acute Respiratory Syndrome Coronavirus 2 (SARS-CoV-2) Infection in Children and Adolescents: A Systematic Review. JAMA Pediatr 2020.

5. Zheng F, Liao C, Fan QH, Chen HB, Zhao XG, Xie ZG, Li XL, Chen CX, Lu XX, Liu ZS et al: Clinical Characteristics of Children with Coronavirus Disease 2019 in Hubei, China. Curr Med Sci 2020.

6. Tagarro A, Epalza C, Santos M, Sanz-Santaeufemia FJ, Otheo E, Moraleda C, Calvo C: Screening and Severity of Coronavirus Disease 2019 (COVID-19) in Children in Madrid, Spain. JAMA Pediatr 2020.

7. Toubiana J, Poirault C, Corsia A, Bajolle F, Fourgeaud J, Angoulvant F, Debray A, Basmaci R, Salvador $\mathrm{E}$, Biscardi $\mathrm{S}$ et al: Kawasaki-like multisystem inflammatory syndrome in children during the covid-19 pandemic in Paris, France: prospective observational study. BMJ 2020, 369:m2094.

8. Yuan J, Kou S, Liang Y, Zeng J, Pan Y, Liu L: PCR Assays Turned Positive in 25 Discharged COVID-19 Patients. Clin Infect Dis 2020.

9. Xu Z, Shi L, Wang Y, Zhang J, Huang L, Zhang C, Liu S, Zhao P, Liu H, Zhu L et al: Pathological findings of COVID-19 associated with acute respiratory distress syndrome. Lancet Respir Med 2020, 8(4):420-422.

10. Liu W, Zhang Q, Chen J, Xiang R, Song H, Shu S, Chen L, Liang L, Zhou J, You L et al: Detection of Covid-19 in Children in Early January 2020 in Wuhan, China. N Engl J Med 2020, 382(14):1370-1371.

11. Dong Y, Mo X, Hu Y, Qi X, Jiang F, Jiang Z, Tong S: Epidemiology of COVID-19 Among Children in China. Pediatrics 2020, 145(6).

12. Su L, Ma X, Yu H, Zhang Z, Bian P, Han Y, Sun J, Liu Y, Yang C, Geng J et al: The different clinical characteristics of corona virus disease cases between children and their families in China - the character of children with COVID-19. Emerg Microbes Infect 2020, 9(1):707-713.

13. Wang G, Zhang Y, Zhao J, Zhang J, Jiang F: Mitigate the effects of home confinement on children during the COVID-19 outbreak. Lancet 2020, 395(10228):945-947.

14. Verdoni L, Mazza A, Gervasoni A, Martelli L, Ruggeri M, Ciuffreda M, Bonanomi E, D'Antiga L: An outbreak of severe Kawasaki-like disease at the Italian epicentre of the SARS-CoV-2 epidemic: an observational cohort study. Lancet 2020.

15. Bar-On YM, Flamholz A, Phillips R, Milo R: SARS-CoV-2 (COVID-19) by the numbers. Elife 2020, 9. 
16. D'Arienzo M, Coniglio A: Assessment of the SARS-CoV-2 basic reproduction number, $\mathbf{R} \mathbf{0}$, based on the early phase of COVID-19 outbreak in Italy. Biosaf Health 2020, 2(2):57-59.

17. Rahman B, Sadraddin E, Porreca A: The basic reproduction number of SARS-CoV-2 in Wuhan is about to die out, how about the rest of the World? Rev Med Virol 2020, 30(4):e2111.

18. Biggerstaff M, Cauchemez S, Reed C, Gambhir M, Finelli L: Estimates of the reproduction number for seasonal, pandemic, and zoonotic influenza: a systematic review of the literature. BMC Infect Dis 2014, 14:480.

19. Nishiura H: Case fatality ratio of pandemic influenza. Lancet Infect Dis 2010, 10(7):443-444.

20. Neuzil KM, Reed GW, Mitchel EF, Jr., Griffin MR: Influenza-associated morbidity and mortality in young and middle-aged women. JAMA 1999, 281(10):901-907.

21. Cao Y, Hiyoshi A, Montgomery S: COVID-19 case-fatality rate and demographic and socioeconomic influencers: worldwide spatial regression analysis based on country-level data. BMJ Open 2020, 10(11):e043560.

22. Baud D, Qi X, Nielsen-Saines K, Musso D, Pomar L, Favre G: Real estimates of mortality following COVID-19 infection. Lancet Infect Dis 2020, 20(7):773.

23. Onder G, Rezza G, Brusaferro S: Case-Fatality Rate and Characteristics of Patients Dying in Relation to COVID-19 in Italy. JAMA 2020, 323(18):1775-1776.

24. Yang S, Cao P, Du P, Wu Z, Zhuang Z, Yang L, Yu X, Zhou Q, Feng X, Wang X et al: Early estimation of the case fatality rate of COVID-19 in mainland China: a data-driven analysis. Ann Trans/ Med 2020, 8(4):128.

25. Rajgor DD, Lee MH, Archuleta S, Bagdasarian N, Quek SC: The many estimates of the COVID-19 case fatality rate. Lancet Infect Dis 2020, 20(7):776-777.

26. Wu X, Cai Y, Huang X, Yu X, Zhao L, Wang F, Li Q, Gu S, Xu T, Li Y et al: Co-infection with SARS-CoV-2 and Influenza A Virus in Patient with Pneumonia, China. Emerg Infect Dis 2020, 26(6):1324-1326.

27. Cuadrado-Payan E, Montagud-Marrahi E, Torres-Elorza M, Bodro M, Blasco M, Poch E, Soriano A, Pineiro GJ: SARS-CoV-2 and influenza virus co-infection. Lancet 2020, 395(10236):e84.

28. Wehl G, Laible M, Rauchenzauner M: Co-infection of SARS CoV-2 and influenza A in a Pediatric Patient in Germany. Klin Padiatr 2020, 232(4):217-218.

29. Kondo Y, Miyazaki S, Yamashita R, Ikeda T: Coinfection with SARS-CoV-2 and influenza A virus. BMJ Case Rep 2020, 13(7).

30. Shen KL, Namazova-Baranova L, Yang YH, Wong GWK, Rosenwasser LJ, Rodewald LE, Goh AEN, Kerem E, O'Callaghan C, Kinane TB et al: Global Pediatric Pulmonology Alliance recommendation to strengthen prevention of pediatric seasonal influenza under COVID-19 pandemic. World J Pediatr 2020, 16(5):433-437.

31. Christophers B, Gallo Marin B, Oliva R, Powell WT, Savage TJ, Michelow IC: Trends in clinical presentation of children with COVID-19: a systematic review of individual participant data. Pediatr Res 2020. 
32. Lukassen S, Chua RL, Trefzer T, Kahn NC, Schneider MA, Muley T, Winter H, Meister M, Veith C, Boots AW et al: SARS-CoV-2 receptor ACE2 and TMPRSS2 are primarily expressed in bronchial transient secretory cells. EMBO J 2020, 39(10):e105114.

33. Hoffmann M, Kleine-Weber H, Schroeder S, Kruger N, Herrler T, Erichsen S, Schiergens TS, Herrler G, Wu NH, Nitsche A et al: SARS-CoV-2 Cell Entry Depends on ACE2 and TMPRSS2 and Is Blocked by a Clinically Proven Protease Inhibitor. Cell 2020, 181(2):271-280 e278.

34. Mangalmurti N, Hunter CA: Cytokine Storms: Understanding COVID-19. Immunity 2020, 53(1):19-25.

35. Zhang Y, Xu Z, Cao Y: Host-Virus Interaction: How Host Cells Defend against Influenza A Virus Infection. Viruses 2020, 12(4).

36. Malik G, Zhou Y: Innate Immune Sensing of Influenza A Virus. Viruses 2020, 12(7).

37. Lee JS, Park S, Jeong HW, Ahn JY, Choi SJ, Lee H, Choi B, Nam SK, Sa M, Kwon JS et al: Immunophenotyping of COVID-19 and influenza highlights the role of type I interferons in development of severe COVID-19. Sci Immunol 2020, 5(49).

38. Zhu L, Yang P, Zhao Y, Zhuang Z, Wang Z, Song R, Zhang J, Liu C, Gao Q, Xu Q et al: Single-Cell Sequencing of Peripheral Mononuclear Cells Reveals Distinct Immune Response Landscapes of COVID-19 and Influenza Patients. Immunity 2020, 53(3):685-696 e683.

39. Chen G, Wu D, Guo W, Cao Y, Huang D, Wang H, Wang T, Zhang X, Chen H, Yu H et al: Clinical and immunological features of severe and moderate coronavirus disease 2019. J Clin Invest 2020, 130(5):2620-2629.

40. Ong EZ, Chan YFZ, Leong WY, Lee NMY, Kalimuddin S, Haja Mohideen SM, Chan KS, Tan AT, Bertoletti A, Ooi EE et al: A Dynamic Immune Response Shapes COVID-19 Progression. Cell Host Microbe 2020, 27(6):879-882 e872.

41. Viner RM, Whittaker E: Kawasaki-like disease: emerging complication during the COVID-19 pandemic. Lancet 2020, 395(10239):1741-1743.

\section{Tables}

Table 1. Baseline characteristics of SARS-CoV-2 and influenza-A-infected children. 


\begin{tabular}{|c|c|c|c|c|c|}
\hline & \multicolumn{2}{|c|}{ SARS-CoV-2 Group, $\mathrm{N}=30$} & \multicolumn{2}{|c|}{ Influenza A Group, $\mathrm{N}=32$} & \multirow{2}{*}{$\frac{p \text { value }}{0.155}$} \\
\hline $\begin{array}{ll}\text { Age } & \text { (median, } \\
\text { IQR) } & \\
\end{array}$ & 5.29 & \begin{tabular}{|l}
$(3.04-$ \\
$7.61)$ \\
\end{tabular} & 7.09 & $\begin{array}{l}(4.08- \\
11.05)\end{array}$ & \\
\hline \multicolumn{6}{|l|}{$\begin{array}{l}\text { Sex (Number, } \\
\text { Percentage) }\end{array}$} \\
\hline Male & 11 & $36.67 \%$ & 19 & $59.38 \%$ & \multirow[t]{2}{*}{0.076} \\
\hline Female & 19 & $63.33 \%$ & 13 & $40.62 \%$ & \\
\hline \multicolumn{6}{|c|}{ Onset of signs and symptoms (Number, Percentage) } \\
\hline Fever & 13 & $43.33 \%$ & 32 & $100.00 \%$ & $<0.001$ \\
\hline Dry cough & 8 & $26.67 \%$ & 32 & $100.00 \%$ & $<0.001$ \\
\hline Pharyngalgia & 2 & $6.67 \%$ & 5 & $15.63 \%$ & 0.268 \\
\hline Fatigue & 2 & $6.67 \%$ & 2 & $6.25 \%$ & 0.948 \\
\hline Diarrhea & 1 & $3.33 \%$ & 0 & $0.00 \%$ & 0.326 \\
\hline $\begin{array}{ll}\text { Interval } & \text { of } \\
\text { onset } & \text { to } \\
\text { admission } & \\
\text { (days), } & \\
\text { (median, IQR) }\end{array}$ & 1 & $1-1.25$ & 3 & $2-5.75$ & 0.417 \\
\hline \multicolumn{6}{|c|}{ laboratory parameters once admission (mean+SD, 95\%CI) } \\
\hline WBC $\left(10^{\wedge} 9 / \mathrm{L}\right)$ & $6.27 \pm 2.87$ & \begin{tabular}{|l|}
$(5.05-$ \\
$7.86)$
\end{tabular} & $8.52 \pm 4.61$ & $\begin{array}{l}(4.69- \\
10.83)\end{array}$ & 0.029 \\
\hline $\begin{array}{l}\text { Neutrophil } \\
\left(10^{\wedge} 9 / \mathrm{L}\right)\end{array}$ & $29.60 \pm 20.83)$ & $\begin{array}{l}(20.06- \\
38.72)\end{array}$ & $58.07 \pm 17.69$ & $\begin{array}{l}(46.04- \\
73.08)\end{array}$ & $<0.001$ \\
\hline $\begin{array}{l}\text { Lymphocyte } \\
\left(10^{\wedge} 9 / \mathrm{L}\right)\end{array}$ & $35.34 \pm 24.00$ & $\begin{array}{l}(22.65- \\
43.72)\end{array}$ & $32.11 \pm 16.43$ & $\begin{array}{l}(17.71- \\
43.77)\end{array}$ & 0.541 \\
\hline $\begin{array}{l}\text { Platelet } \\
\left(10^{\wedge} 9 / \mathrm{L}\right)\end{array}$ & $247.64 \pm 62.35$ & $\begin{array}{l}(219.00- \\
275.27)\end{array}$ & $255.12 \pm 72.81$ & $\begin{array}{l}(195.06- \\
309.54)\end{array}$ & 0.673 \\
\hline HB (g/L) & $132.57 \pm 10.71$ & $\begin{array}{l}(128.97- \\
139.13)\end{array}$ & $120.34 \pm 14.97$ & $\begin{array}{l}(110.41- \\
133.39)\end{array}$ & 0.001 \\
\hline ALB (g/L) & $45.19 \pm 2.69$ & $\begin{array}{l}(43.92- \\
46.31)\end{array}$ & $43.39 \pm 3.34$ & $\begin{array}{l}(40.19- \\
44.03)\end{array}$ & 0.280 \\
\hline ALT (U/L) & $17.47 \pm 10.88$ & $\begin{array}{l}(13.61- \\
23.90)\end{array}$ & $16.73 \pm 13.27$ & $\begin{array}{l}(5.01- \\
34.60)\end{array}$ & 0.815 \\
\hline AST (U/L) & $33.10 \pm 12.95$ & $\begin{array}{l}(26.47- \\
38.48)\end{array}$ & $42.37 \pm 16.60$ & $\begin{array}{l}(22.52- \\
49.56)\end{array}$ & 0.020 \\
\hline$\overline{\mathrm{LDH}}(\mathrm{U} / \mathrm{L})$ & $322.50 \pm 193.43$ & $\begin{array}{l}(236.74- \\
408.26)\end{array}$ & $369.70 \pm 165.79$ & $\begin{array}{l}(251.10- \\
488.30)\end{array}$ & 0.285 \\
\hline CK (U/L) & $70.36 \pm 40.92$ & $\begin{array}{l}(34.17- \\
103.84)\end{array}$ & $132.19 \pm 88.06$ & $\begin{array}{l}77.50- \\
147.41) \\
\end{array}$ & 0.035 \\
\hline BUN (mmol/L) & $4.55 \pm 2.27$ & [2.87-8.29ם & $3.19 \pm 0.92$ & $\begin{array}{l}2.85- \\
3.70 \square^{2 .}\end{array}$ & 0.006 \\
\hline ESR (mm/h) & $11.11 \pm 6.61$ & $\begin{array}{l}(6.57- \\
14.60)\end{array}$ & $21.65 \pm 12.80$ & $\begin{array}{l}(14.54- \\
29.21) \\
\end{array}$ & 0.003 \\
\hline $\mathrm{Cr}(\mathrm{umol} / \mathrm{L})$ & $36.70 \pm 15.66$ & $\begin{array}{l}(25.22- \\
42.38)\end{array}$ & $36.42 \pm 13.82$ & $\begin{array}{l}(28.66- \\
37.27)\end{array}$ & 0.942 \\
\hline PCT (ng/ml) & $0.07 \pm 0.08$ & $\begin{array}{l}(0.02- \\
0.10)\end{array}$ & $0.32 \pm 0.36$ & $\begin{array}{l}(0.15- \\
0.38)\end{array}$ & 0.001 \\
\hline CRP (mg/L) & $5.34 \pm 10.34$ & $\begin{array}{l}(0.98- \\
9.71)\end{array}$ & $17.22 \pm 17.61$ & $\begin{array}{l}(10.87- \\
23.57)\end{array}$ & 0.003 \\
\hline $\begin{array}{l}\text { Oxygenation } \\
\text { Index }\end{array}$ & $448.52 \pm 239.08$ & $\begin{array}{l}(345.13- \\
551.91) \\
\end{array}$ & $441.63 \pm 55.55$ & $\begin{array}{l}(395.19- \\
488.07)\end{array}$ & 0.899 \\
\hline 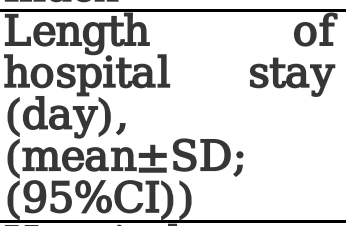 & $15.53 \pm 4.35$ & $\begin{array}{l}(13.91- \\
17.16)\end{array}$ & $5.31 \pm 2.02$ & $\begin{array}{l}(4.58- \\
6.04)\end{array}$ & $<0.001$ \\
\hline $\begin{array}{l}\text { Hospital cost } \\
\text { (RMB), }\end{array}$ & $12015.87 \pm 4449.26$ & $\begin{array}{l}(10179.31- \\
13852.43)\end{array}$ & $4168.61 \pm 1524.21$ & $\begin{array}{l}(3619.07- \\
4718.15)\end{array}$ & $<0.001$ \\
\hline
\end{tabular}


Data of continuous variables are given as mean \pm SD with 95\% CI. While for data not normally distributed, median with interquartile range (IQR) is used. Categorical variables are given as counts and percentages. Abbreviations: WBC, white blood cell; HB, hemoglobin; ALB, Albumin; ALT, alanine aminotransferase; AST, aminotransferase; LDH, lactate dehydrogenase; CK, creatine kinase; BUN, blood urea nitrogen; ESR, erythrocyte sedimentation rate; $\mathrm{Cr}$, creatinine; $\mathrm{PCT}$, procalcitonin; $\mathrm{CRP}, \mathrm{C}$-reactive protein. $\mathrm{P}$ values in bold are considered to be significant.

Table 2. Correlation analysis between body temperature and hematological parameters.

\begin{tabular}{lcccccccc}
\multicolumn{2}{c}{ WBC } & \multicolumn{2}{c}{ HB } & \multicolumn{2}{c}{ CRP } & \multicolumn{2}{c}{ PCT } \\
\hline & Coefficient & $\begin{array}{c}\text { P- } \\
\text { value }\end{array}$ & coefficient & $\begin{array}{c}\text { P- } \\
\text { value }\end{array}$ & coefficient & $\begin{array}{c}\text { P- } \\
\text { value }\end{array}$ & coefficient & $\begin{array}{c}\text { P- } \\
\text { value }\end{array}$ \\
\hline $\begin{array}{l}\text { SARS-CoV- } \\
2 \text { group }\end{array}$ & 0.414 & $\mathbf{0 . 0 2 8}$ & -0.387 & $\mathbf{0 . 0 4 2}$ & 0.509 & $\mathbf{0 . 0 1 1}$ & 0.51 & $\mathbf{0 . 0 1 3}$ \\
\hline $\begin{array}{l}\text { Influenza } \\
\text { A group }\end{array}$ & -0.081 & 0.658 & -0.161 & 0.379 & 0.105 & 0.568 & 0.477 & $\mathbf{0 . 0 1}$ \\
& & & & & & & &
\end{tabular}

Pearson's correlation coefficients between body temperature on admission day and immune function parameters. $\mathrm{P}$ values in bold are considered to be significant. Abbreviations: WBC, white blood cell; HB, hemoglobin; CRP, C-reactive protein; PCT, procalcitonin.

\section{Figures}




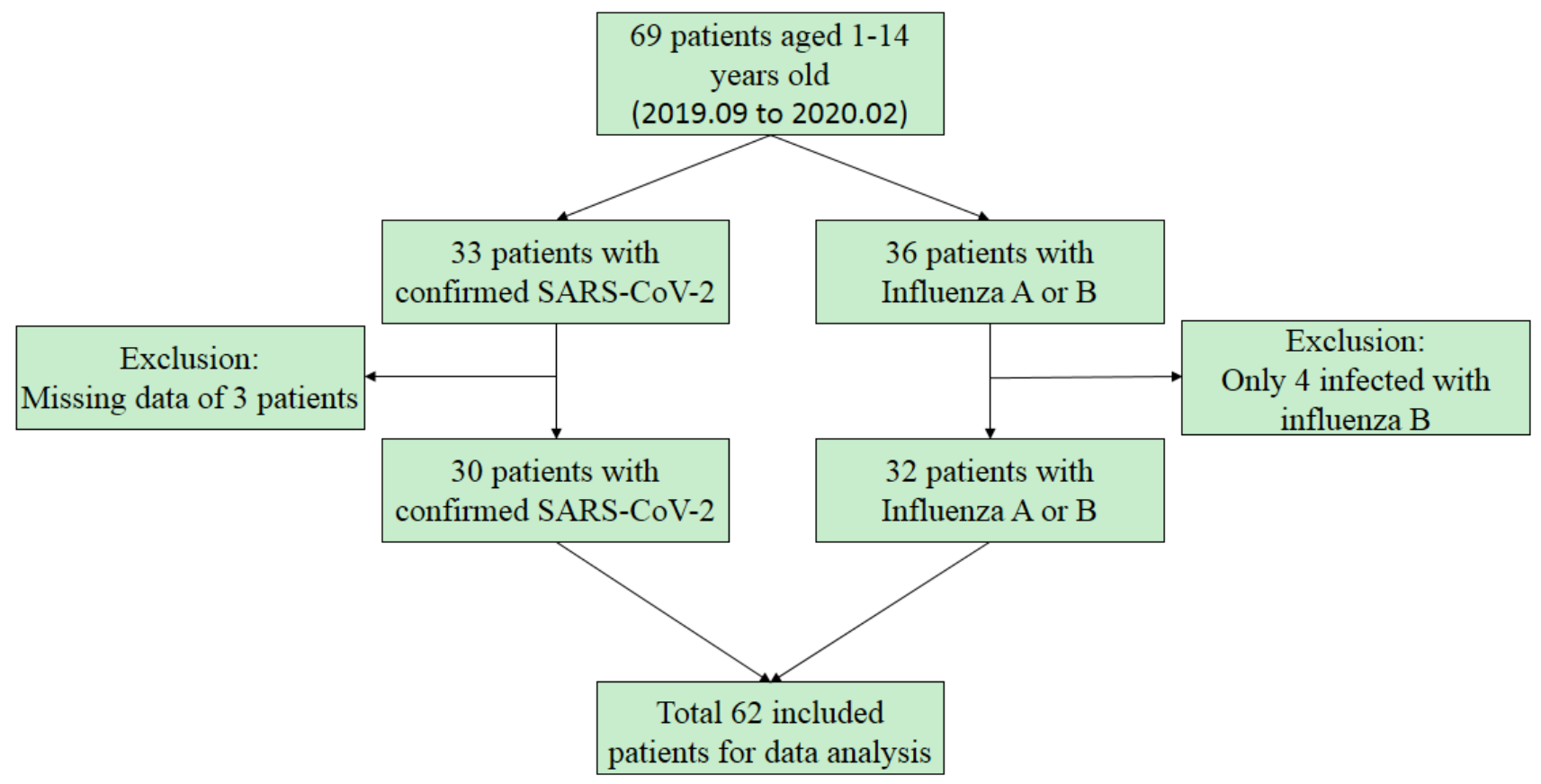

\section{Figure 1}

The flow chart shows the screening procedures of participants in this study.

A
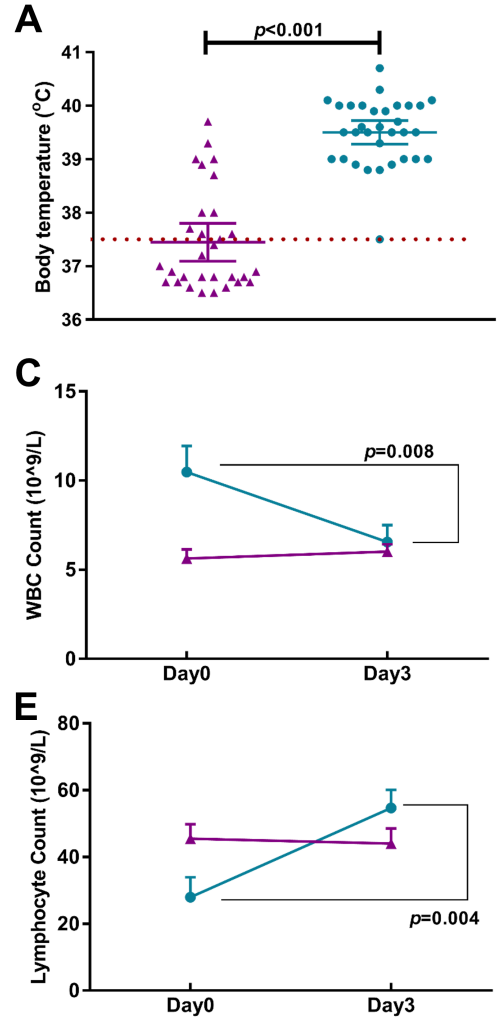

B
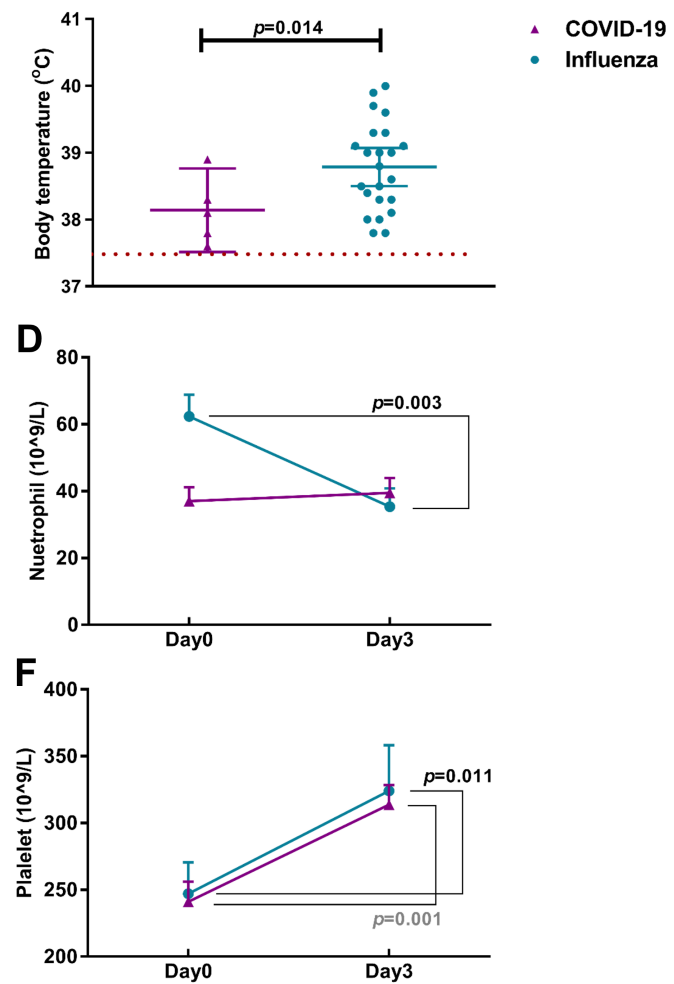

Figure 2 
Changes of body temperature and laboratory parameters in the peri-hospitalization period. Box plot with the mean line and $95 \% \mathrm{Cl}$ of the body temperature observations showing comparisons between SARSCoV-2 and influenza-A-infected children before hospital admission (A) and after 3-day of hospital stay (B). Only 5 children's body temperature exceeded $37.5^{\circ} \mathrm{C}$ while 23 patients remained continuous fever after 3 days of hospital stay. Comparisons on counts of white blood cell (WBC) (C), neutrophil (D), lymphocyte $(E)$, as well as platelet $(F)$ showed significant increase in influenza-A-infected children, represented with blue triangles. While those of SARS-CoV-2-infected children were represented with purple dot. Error bars: Mean \pm SEM. 